\title{
Closed Loop Supply Chains for Sustainable Mass Customization
}

\author{
Kjeld Nielsen and Thomas Ditlev Brunø \\ Department of Mechanical and Manufacturing Engineering, Aalborg University, Denmark \\ kni@m-tech.aau.dk
}

\begin{abstract}
Closed loop supply chains reducing waste, energy consumption and natural resource depletion which all contribute to more sustainable production and products. For mass customization however, the challenges of closed loop supply chains are emphasized by the large variety of inbound end-of-life products from customers which complicates handling and forecasting. This paper analyses these challenges in the specific context mass customization using theoretical considerations and three case studies.
\end{abstract}

Keywords: mass customization, sustainability, remanufacturing, reuse, recycling.

\section{Introduction}

Mass Customization (MC) popularized by Pine [6] has proven a successful business strategy in various industries and markets and for several different product types. Mass customization is fundamentally different from mass production in several different ways, spanning from product design and production to sales and marketing and fit with customer needs. Sustainability is a concept that is gaining more and more attention, and companies are experiencing a greater demand for sustainable products as well as legislation requiring lower environmental impacts [3]. Several concepts are commonly applied to achieve greater sustainability in product design and manufacturing. Among these is Eco-design, which is a concept that attempts to integrate environmental aspects into the product development process thereby creating products with lower negative environmental impacts and thus more environmentally sustainable products [3]. Generally, what happens to a product at its end of life (EOL) is very important in relation to sustainability. This is the case for two reasons: 1) if a product is disposed by land filling or incineration, the materials in the product may harm the environment. 2) The amount of materials available in the world is finite, and if raw materials are extracted at the same pace in the future as they are today, certain materials will become scarce. If an EOL product is simply disposed by land filling or incineration, the materials used in the product are lost, and thus more new material must be extracted for manufacturing new products. Reusing or recycling a product addresses both the issues regarding land filling or incineration as well as resource consumption, since EOL products are either recycled and the materials are transformed 
into other products or the products are used in their original form. However, even though reverse logistics may help to safely dispose of EOL products, extending the concept to closed loop supply chains has proven to reduce the environmental impact even more [7]. A closed loop supply chain is a combination of a reverse supply chain and a traditional forward supply chain where the components or materials retrieved from products in the reverse supply chain are used to manufacture products for the forward supply chain, thus closing the materials loop.

Rose [7] performed a quantitative Analysis of the environmental impact from a variety of different consumer electronics for the different recycling loops also referred to as EOL strategies. She found that with no exceptions, the environmental impact of a product would increase each time a larger loop was applied. Based on this, she introduced the hierarchy of EOL strategies illustrated in figure 1 [7] and concluded that a product should be designed to apply EOL strategies as high in the hierarchy as possible, corresponding to shorter closed loop supply chains [7].

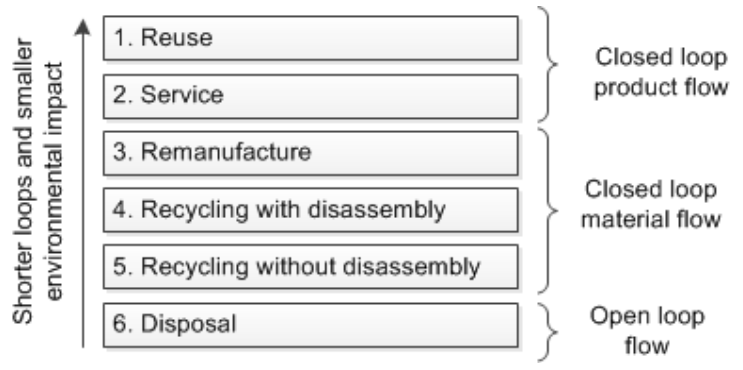

Fig. 1. Hierarchy of product EOL strategies [7]

Apart from the environmental perspective, applying short closed loop supply chains are also usually favorable from an economic perspective. The reason for this is that materials used in products higher in the EOL hierarchy have more value added than lower in the hierarchy. As examples, product reuse requires no or very little additional value added before the product can be used by a new (second hand) customer, whereas a disposed product represents zero or very little value if it is incinerated for energy production.

\section{Research Method}

The research objective of this paper is to identify how well mass customized products can become more sustainable by utilizing closed loop supply chains. The research question is: "How can end-of-life strategies with closed loop supply chains be applied to mass customized products?" To answer this question, it is first clarified how well the EOL hierarchy and mass customized products combine. Secondly the concepts of closed loop supply chains with different EOL strategies are analyzed for various mass customized products. Finally the findings from the analysis and the case studies are identified and presented. The analysis is performed as an empiric research based on 
Rose's product EOL strategy hierarchy as presented in figure 1. It is analyzed which issues typically arise for mass customized products in end-of-life. This is done for each of the 6 levels in the EOL hierarchy (fig. 1). The concepts of closed loop supply chains are further analyzed in three mass customization cases all with EOL strategies and different levels in the hierarchy. The case studies present and analyze how the EOL strategies have been implemented in consumer electronics, automobile and furniture industry. The findings from the analysis and case studies are presented as a general overview of advantages and disadvantages of mass customized products combined with EOL strategies and a comparison of EOL strategies of the case studies.

\section{Closed Loop Supply Chain and Mass Customization}

Much research has been done in the areas reverse logistics and closed loop supply chains, however, no studies have been identified focusing on these issues related specifically to mass customized products. Mass customized products are distinguished from non-mass customized products, primarily by their vast variety, as each product is uniquely produced for a specific customer. This is expected to bring up new challenges in relation to reusing and recycling products. In the following sections, the challenges specific to mass customized products will be discussed. The analysis will be structured by the levels in the product EOL strategy hierarchy shown in figure 1 .

\subsection{Reuse}

Reuse (1) is the EOL strategy which will use least resources compared to other EOL strategies, simply because following the definition expressed by Rose [7] as " $\ldots$ the second hand trading of a product for use as originally designed", the products involved in a reuse process change owners without any involvement of the original manufacture and other further resources involved. Implementing reuse as an EOL strategy should be easy for standard products but for MC products there are several difficulties which have to be addressed.

One issue related to MC products is that the customized product specifically made for a specific customers requirements, can be difficult to reuse. Difficult to reuse, because the products will not fit the new customers' requirements; as examples, it could be tailor fitted products, as suits, shoes, furniture etc.

Implementing an EOL strategy should on the other hand lead to MC products which should be easy to reuse and even in the reuse process are able to customize further for the second hand owner.

\subsection{Service}

If a product is to be replaced due to "wear and tear", i.e. the product is somehow worn or defective and thus cannot be reused, which is the preferred EOL strategy according to the hierarchy, the strategy "service" should be considered [7]. In this strategy, the life of a product is extended by repairing or servicing the product thus pushing the 
time where a new product will have to be manufactured to fulfill a user's needs. There is no apparent and strong relation between this strategy and mass customization, however the variety of parts included in the product may cause some issues if spare parts are necessary. This would be the case if the parts, which are to be replaced to repair the product, are custom fabricated, as opposed to a customized product assembled from standard components. If a custom fabricated component is required for repairing or servicing the product, this would likely be more expensive than repairing a product using standard components, since the spare part would need to be manufactured specifically for that product which would likely introduce higher logistical costs as well as a problem regarding the identification of specifications for manufacturing that specific part.

An example of mass customized products which have a modular architecture that supports upgrading is personal computers. If a user finds that a computer is lacking certain functionality or performance, in many cases this will be possible to address by adding or replacing modules in the computer such as CPU, processor or other expansion cards. This is obviously more appropriate from an environmental perspective since a new computer will not have to be produced to fulfill the user's new needs.

\subsection{Remanufacture}

The EOL strategy remanufacturing implies according to Rose [7] that EOL products are returned from the customer to a remanufacturing plant where they are disassembled; the parts are reconditioned and used in the manufacturing of new products using newly manufactured parts as well. In contrast to the service EOL strategy, the product is here completely disassembled and components are collected and kept in stock until needed. By choosing the remanufacturing strategy, the material and energy used for originally manufacturing the products is not lost which apart from reducing negative environmental impact can be economically beneficial as well [9].

The degree to which an MC product is suitable for remanufacturing will be very dependent on how the product architecture is defined. One way to mitigate the challenges derived from component variety described above by means of product architecture would be to enable remanufacturing of the components common to all products in a product family, commonly referred to as the product platform, which is commonly used in MC products [1], whereas the modules providing customization could be recycled for materials. This however would require the components in the platform to be sufficiently durable for multiple life cycles.

\subsection{Recycling with Disassembly}

When applying the recycling with disassembly EOL strategy, EOL products are taken to recycling facilities where they are disassembled and recycled. In contrast to recycling without disassembly, this strategy implies that the value and energy accumulated in the products is to some extent retained. Recycling with disassembly also allows removing components or substances which would otherwise contaminate the 
recyclable materials, as well as valuable components can be removed and reused or remanufactured [7].

When considering recycling with disassembly in relation to $\mathrm{MC}$ products, several different factors influence the possibilities for recycling. As the products need to be disassembled, which is usually a manual process, the disassembly process is likely to account for much of the total costs associated with recycling. As MC products will often have varying product structures compared to non MC products, the disassembly process will also vary more than for non MC products. As a consequence, it will be more difficult to optimize the disassembly process as well as applying automation.

\subsection{Recycling without Disassembly and Disposal}

Recycling without disassembly is the EOL strategy with the longest materials loop and thus the least desirable of the closed loop supply chain strategies, however still preferable over disposal. Recycling without disassembly is usually performed by shredding; by doing this the shredded products can be sorted into material fractions which can be recycled. Since all products are treated alike when recycled without disassembly, no specific challenges regarding MC products are identified for this EOL strategy. The EOL strategy disposal is the least desirable in the hierarchy, since the value and energy accumulated in the products is not recovered. As for the recycle without disassembly strategy, all products are treated alike when disposed, and no specific challenges regarding MC products are identified for this EOL strategy.

\section{Case Analyses}

To address how different types of companies have been using reverse logistics in practice, a number of case studies have been identified in literature.

Dell Inc. sells and produces personal computers which are all customized according to the customer specific configuration. Dell has implemented a closed loop supply chain to make use of EOL computers which are traded in by Dell's customers. This case is thoroughly described by Kumar \& Craig [5]. When comparing the paths of EOL computers at Dell to the classification of EOL strategies shown in figure 1, Dell makes use of several of these strategies:

- Reuse: EOL computers which do not require any parts changed are reinstalled with an operating system and resold, physically unchanged.

- Service or Remanufacture: computers which require replacement of components are changed physically and are, depending on how many components are changed, either serviced or remanufactured.

- Recycle with disassembly: computers which are not reused, serviced or remanufactured are disassembled and shipped to appropriate recycling facilities.

This multilevel approach to handling EOL computers allows Dell to utilize the shortest closed loop supply chain as possible. What enables this is that the modularity of Dell computers allows components to be easily replaced and allows reuse of 
components from EOL computers. Furthermore, Dell's volume makes it profitable to run remanufacturing facilities.

Numerous car manufacturers are mass customizing their cars. This is enabled by a modular product platform which allows customization by assembling the car from a common platform and a number of different modules creating the variety. Contrary to the Dell case, car manufacturers do not take back whole cars for remanufacturing, which can be due to a number of reasons. Cars usually have a much longer life than personal computers and are thus regularly serviced for extending their life. Relating the automobile industry to the classification of EOL strategies in figure 1, it shows that the car industry also utilizes multiple levels.

- Service: When a used car is traded in by a dealership, it is serviced and resold, typically in an unchanged configuration; however, the car manufacturer is not involved in this.

- Remanufacturing: Worn components are traded in for a discount on a remanufactured component and remanufactured to as new condition by specialized companies

- Recycling with disassembly: EOL vehicles are returned to third party car recycling facilities and disassembled for spare parts and material recycling.

The automobile industry is similar to the Dell case since mass customized products are resold in a fixed configuration which cannot be reconfigured.

Ahrend is a Dutch manufacturer of office furniture, which has done a significant effort on reducing the negative environmental impact from production and product life cycles. Ahrend produces office chairs and desks for the professional market and their furniture are individually customized and can thus be considered mass customized products. Ahrend has as one of the means to control supply of EOL products, introduced a residual value on repurchase program for its customers allowing them to return their product to Ahrend after ended use and receive a partial refund. After receiving the used products Ahrend is to refurbish certain components and renew others and sell new products which contain refurbished as well as new components. These new products are again customized. Comparing the Ahrend case to the EOL hierarchy of figure 1 shows that Ahrend contrary to the two other cases makes use of remanufacturing used products to create new mass customized products by reusing on module level.

\section{$5 \quad$ Findings}

In figure 2, an overview of the different EOL strategies and their implications for MC products is presented. For the upper 4 levels a number of challenges exist which are specific to MC products, however a number of characteristics of MC products also provide benefits for the different closed loop supply chain EOL strategies compared to non MC products. Finally, no differences were found for the lower two EOL strategies between $\mathrm{MC}$ and non MC products.

Figure 3 shows a comparison of EOL strategies chosen in the three different cases presented in this paper as well as the EOL options for a generic MC product. For 
a generic MC product, i.e. any MC product, for which the manufacturer has not actively chosen an EOL strategy, the options for the customer when disposing the product will be either to sell it as second hand, given the second hand purchaser can accept the product configuration or bring it to recycling facilities or disposal. What can also be concluded from the comparison is that in only the Ahrend case, the products are remanufactured and offered as individually mass customized products again, whereas the other two cases offer used products in an as-is configuration. It is furthermore common to use mixed EOL strategies, since the difference in wear and obsolescence makes different EOL strategies suitable for different products in the supply of used products.

\begin{tabular}{|c|c|c|}
\hline & Advantages & Dlsadvantages \\
\hline Reuse & $\begin{array}{l}\text { Reconfigurability allows customization to new } \\
\text { user }\end{array}$ & Poor fit to diverse customer demands \\
\hline \multirow[t]{2}{*}{ Service } & $\begin{array}{l}\text { Modularity enables replacement of defective } \\
\text { modules }\end{array}$ & $\begin{array}{l}\text { Product variety increases variety of spare } \\
\text { parts }\end{array}$ \\
\hline & $\begin{array}{l}\text { Modular products enable component } \\
\text { replacement }\end{array}$ & $\begin{array}{l}\text { Product variety in EOL product supply } \\
\text { complicates demand planning }\end{array}$ \\
\hline Remanufacturing & $\begin{array}{l}\text { Product platform architecture enables } \\
\text { remanufacturing of modules common to one } \\
\text { product family }\end{array}$ & $\begin{array}{l}\text { Custom manufactured components are } \\
\text { unsuitable for remanufacturing }\end{array}$ \\
\hline $\begin{array}{l}\text { Recycle with } \\
\text { disassembly }\end{array}$ & $\begin{array}{l}\text { Easier disassembly due to modular product } \\
\text { architecture }\end{array}$ & $\begin{array}{l}\text { Difficult to optimize or automate disassembly } \\
\text { process due to product structure variety }\end{array}$ \\
\hline $\begin{array}{l}\text { Recycle without } \\
\text { disassembly }\end{array}$ & None & None \\
\hline Disposal & None & None \\
\hline
\end{tabular}

Fig. 2. Overview of product EOL strategies and implications for mass customization products compared to mass produced products

As mentioned above, many MC products can be reused in an as-is configuration. While this would likely be beneficial in terms of environmental impact, the business potential is negligible unless the manufacturer is involved in the second hand trading of the product as in the Dell case.

\begin{tabular}{|c|c|c|c|c|c|}
\hline Generic MC & & & \multicolumn{3}{|c|}{ Generic MC } \\
\hline \multicolumn{4}{|c|}{ Dell Inc. } & \multirow{4}{*}{$\begin{array}{l}\text { Recycle without } \\
\text { disassembly }\end{array}$} & \\
\hline \multirow[b]{3}{*}{ Reuse } & \multicolumn{3}{|c|}{ Auto industry } & & \multirow[b]{3}{*}{ Disposal } \\
\hline & & Ahrend & \multirow{2}{*}{$\begin{array}{l}\text { Recycle with } \\
\text { disassembly }\end{array}$} & & \\
\hline & Service & Remanufacture & & & \\
\hline
\end{tabular}

Fig. 3. Comparison of EOL strategies for case products

Finally the case comparison revealed that there are differences in whether the manufacturer manages the closed loop supply chains or a specialized third party company is involved. General for all cases is that the product families apply modular product architectures, which is not surprising since modular architecture enables mass customization and remanufacturing [2], [4]. 


\section{Conclusion}

From the analysis of EOL strategies and cases it can be concluded that it is indeed possible to utilize closed loop supply chains in mass customization settings. However, utilizing closed loop supply chains requires certain aspects to be considered regarding product design as well as manufacturing and supply chain design.

Utilizing closed loop supply chains has a great potential in achieving a higher degree of product sustainability, since this will reduce the amount of waste produced as well as reducing the demand for raw material production and energy consumption. Although only a minor part of mass customizers are utilizing closed loop supply chains, the case studies have shown that it can be an attractive business proposition to e.g. remanufacture products and resell them.

However, to provide the customer with the highest value, and thereby charge a price premium, the remanufactured product should be re-customized to specific customer requirements as done in the case study of Ahrend instead of reselling products as second hand in as-is configurations. This however presents a number of logistical challenges as well as challenges in developing the solution space for configuring remanufactured products. Furthermore, this research addresses only mass customization of physical products. Mass customization of services and software is also relevant but will require entirely different considerations regarding sustainable supply chains.

\section{References}

1. Huang, G.Q., Simpson, T.W., Pine II, B.J.: The Power of Product Platforms in Mass Customisation. International Journal of Mass Customisation 1, 1-13 (2005)

2. Ishii, K.: Modularity: A Key Concept in Product Life-Cycle Engineering. In: Handbook of Life-cycle Engineering (1998)

3. Karlsson, R., Luttropp, C.: EcoDesign: What's Happening? an Overview of the Subject Area of EcoDesign and of the Papers in this Special Issue. J. Clean. Prod. 14, 1291-1298 (2006)

4. Krikke, H., le Blanc, I., van de Velde, S.: Product Modularity and the Design of ClosedLoop Supply Chains. Calif. Manage. Rev. 46, 23-39 (2004)

5. Kumar, S., Craig, S.: Dell, Inc.'s Closed Loop Supply Chain for Computer Assembly Plants. Information, Knowledge, Systems Management 6, 197-214 (2007)

6. Pine, B.J.: Mass customization: The new frontier in business competition. Harvard Business School Press (1993)

7. Rose, C.M.: Design for environment: A method for formulating product end-of-life strategies. In: Design for Environment: A Method for Formulating Product End-of-Life Strategies. Stanford University (2000)

8. Subramoniam, R., Huisingh, D., Chinnam, R.B.: Remanufacturing for the Automotive Aftermarket-Strategic Factors: Literature Review and Future Research Needs. J. Clean. Prod. 17, 1163-1174 (2009) 